chi phí ngoài điều trị như chi phí chăm sóc và mất năng suất lao động. Trong khi thu nhập bình quân đầu người năm 2018 của người Việt Nam là 3.76 triệu đồng/ tháng. Điều này một lần nữa khẳng định CTSN là một gánh nặng về kinh tể.

\section{KẾT LUẬN}

Chấn thương sọ não vẫn là nguyên nhân gây tử vong và để lại di chứng cho người trẻ. Nhiều tiến bộ trong công tác phòng ngừa và chăm sóc CTSN (chẳng hạn như thành lập thêm các đơn vị chăm sóc đặc biệt về phẫu thuật thần kinh, tăng khả năng cung cấp máy theo dõi áp lực nội sọ, phát triển chuyên ngành chẩn đoán hình ảnh và đặc biệt là quá trình vận chuyển bệnh nhân) đã góp phần cải thiện việc điều trị CTSN ở Việt Nam. Tuy nhiên, vẫn còn nhiều cải tiến cần được thực hiện, đặc biệt là trong việc đạt được tiêu chuẩn hóa chăm sóc CTSN trên khắp cả nước. Những cải tiến này có thể được thực hiện thông qua các chương trình đào tạo cho các bác sĩ phẫu thuật thần kinh trẻ tuổi, tăng cường các cơ sở y tế ở các vùng sâu vùng xa, đào tạo bác sĩ về chuẩn hóa cấp cứu ban đầu. Đặc biệt là thực thi luật bắt buộc đội mũ bảo hiểm khi ngồi trên xe gắn máy và nghị định 100 về phòng chống rượu bia khi tham gia giao thông cũng như có chương trình phòng chống ngã cho người cao tuổi.

TÀI LIỆU THAM KHẢO

1. Majdan M, Plancikova D, Brazinova A, et al.
Epidemiology of traumatic brain injuries in Europe: a cross-sectional analysis. The Lancet Public Health. 2016;1(2):e76-e83.

2. Gao G, Wu $\mathbf{X}$, Feng $J$, et al. Clinical characteristics and outcomes in patients with traumatic brain injury in China: a prospective, multicentre, longitudinal, observational study. The Lancet Neurology. 2020;19(8):670-677.

3. Olesen J, Gustavsson A, Svensson $M$, et al. The economic cost of brain disorders in Europe. European journal of neurology: the official journal of the European Federation of Neurological Societies. 2012;19:155-162.

4. Wu X, Hu J, Zhuo $L$, et al. Epidemiology of traumatic brain injury in eastern China, 2004: a prospective large case study. Journal of Trauma and Acute Care Surgery. 2008;64(5):1313-1319.

5. Seesen $M$, Siviroj $P$, Sapbamrer $R$, Morarit $S$. High blood alcohol concentration associated with traumatic brain injury among traffic injury patients during New Year festivals in Thailand. Traffic injury prevention. 2019;20(2):115-121.

6. Hsu I-L, Li C-Y, Chu D-C, Chien L-C. An Epidemiological Analysis of Head Injuries in Taiwan. International Journal of Environmental Research and Public Health. 2018;15(11):2457.

7. Pozzato $\mathbf{I}$ Tate RL, Rosenkoetter $U_{\text {, }}$ Cameron ID. Epidemiology of hospitalised traumatic brain injury in the state of New South Wales, Australia: a population-based study. Australian and New Zealand journal of public health. 2019;43(4):382-388.

8. Hotz GA, Cohn SM, Popkin C, et al. The impact of a repealed motorcycle helmet law in MiamiDade County. Journal of Trauma and Acute Care Surgery. 2002;52(3):469-474.

\title{
NGHIÊN CỨU BÀO CHẾ PELLET VERAPAMIL HYDROCLORID NHÂN ĐỂ TĂNG HIỆU QUẢ ĐIỀU TRI TĂNG HUYẾT ÁP
}

Trương Đức Mạnh¹, Võ Xuân Minh², Phan Thị Hòa1, Nguyễn Văn Bạch ${ }^{1}$, Đinh Đình Chính ${ }^{3}$

\section{TÓM TẮT}

Muc tiêu: Xây dựng được công thức và qui trình bào chế pellet Verapamil hydroclorid nhân. Phương pháp: Bào chế pellet Verapamil hydroclorid nhân bằng phương pháp đùn tạo cầu; đánh giá các tiêu chuẩn như: Hiệu suất, cảm quan và đặc điểm pellet nhân, khối lượng riêng biểu kiến, tốc độ chảy, độ mài mòn, hàm ẩm, hàm lượng, tỷ lệ pellet có kích thước

${ }^{1}$ Học viện Quân y

${ }^{2}$ Đại họ Dước Hà Nội

${ }^{3}$ Bệnh viện Trung ường Quân đội 108

Chịu trách nhiệm chính: Trương Đức Mạnh

Email: manhxn150@gmail.com

Ngày nhận bài: 28/2/2021

Ngày phản biên khoa học: 29/4/2021

Ngày duyệt bài: 3/5/2021 0,8-1,2mm và độ hòa tan: Kết quả: Đã bào chế được pellet Verapamil hydroclorid nhân với các thành phần như: verapamil hydroclorid 40\%, Avicel PH102 45\%, Lactose $12,5 \%$, Talc $2,5 \%$, HPMC E6 $0,2 \mathrm{~g}$ và nước tinh khiết $50 \mathrm{ml}$. Kết luận: pellet Verapamil hydroclorid nhân bào chế được đat các tiêu chuẩn về: Hinh thức, khối lượng riêng biểu kiến, tốc độ chảy, độ mài mòn, hàm ẩm, hàm lương, tỷ lẹ pellet có kích thước $0,8-1,2 \mathrm{~mm}$ và độ hòa tan.

Tư khóa: Verapamil hydroclorid, đùn-tạo câu.

\section{SUMMARY \\ STUDY ON PREPARATION OF VERAPAMIL HYDROCLORID CORE TO IMPROVE TREATMENT EFFICIENCY ON HYPERTENSION}

Objective: Developing the formula and preparation process of Verapamil hydrocloride pellet 
core. Methods: The pellet core were prepared by extrusion spheronization method; Criteria including efficiency, physical apparence and pellet core characteristics, apparent density, flow rate, abrasion, moisture content, content of active ingredient, ratio of 0.8-1.2mm pellet, solubility were evaluated. Results: Verapamil hydrocloride pellet core have been formulated with ingredients: verapamil hydrocloride $40 \%$, Avicel PH102 45\%, Lactose 12.5\%, Talc 2.5\%, HPMC E6 $0.2 \mathrm{~g}$ and $50 \mathrm{~mL}$ purified water. Conclusion: The prepared pellet core of Verapamil hydrochloride meet the standards of: apperance, apparent density, flow rate, abrasion, moiture content, ratio of 0.8 $1.2 \mathrm{~mm}$ pellet and solubility

Keywords: Verapamil hydrocloride, extrusion spheronization method

\section{I. ĐẶT VẤN ĐỀ}

Verapamil hydroclorid (VER.HCl) là một thuốc chẹn kênh calci, được dùng để điều trị đau thắt ngực, tăng huyết áp và rối loạn nhịp tim. Trên $90 \%$ liều uống được hấp thu, tuy nhiên sinh khả dụng chỉ đạt 20 - 35\% do chuyển hóa bước đầu qua gan nhanh. Dược chất có thời gian bán thải ngắn (2,8-7,4 giờ) khiến cho bênh nhân phải uống thuốc nhiều lần trong ngày $[1,2,3]$. Do đó việc bào chế VER.HCl dưới dạng pellet giải phóng kéo dài rất có ý nghĩa trong điều trị $[4,5]$. Để bào chế pellet giải phóng kéo dài, trước tiên phải bào chế pllet nhân, các tính chất của pellet nhân ảnh hưởng rất lớn đến quá trình bao kiểm soát giải phóng dược chất. Cho nên trong nghiên cứu này, chúng tôi đưa ra các kết quả khảo sát ảnh hưởng của một số thông số thuộc quy trình kỹ thuật và công thức pellet nhân, làm cơ sở để xây dựng công thức bào chế cho pellet VER. $\mathrm{HCl}$ nhân.

\section{NGUYÊN VẬT LIỆU VÀ PHƯƠNG PHÁP NGHIÊN CỨU}

2.1. Nguyên liệu và hóa chất: $V E R . H C l$ chuẩn: Do viện kiểm nghiệm thuốc TP HCM cung cấp (QT242010914, hàm lượng 100,52\%); VER.HCl: Tiêu chuẩn USP 38 (Đài loan), HPMC E6, Talc: Tiêu chuẩn USP 38 (Trung Quốc), nước tinh khiết: Tiêu chuẩn DĐVN IV (Việt Nam).

2.2. Thiết bị: Cân phân tích Mettler toledo có độ chính xác $0,1 \mathrm{mg}$ (Đức); cân kỹ thuật Sartorius độ chính xác $0,01 \mathrm{~g}(\mathrm{Anh}) ;$ máy đùn tạo cầu QZT 350 (Trung Quốc); máy đo quang phổ UV-VIS Labomed UVD-2960 (Mỹ); Cân xác định độ ẩm nhanh Sartorius MA30 (Đức); bộ rây phân tích kích thước hat (Trung quốc). Các thiết bi, dung cu khác như: ống nghiệm, cốc có mỏ, phễu lọc, giấy lọc,... đạt tiêu chuẩn phân tích và bào chế.

\subsection{Phương pháp nghiên cứu \\ 2.3.1. Phương pháp bào chế pellet verapamil hydroclorid nhân}

Pellet VER.HCl được bào chế bằng phương pháp đùn - tạo cầu, với các thành phần khảo sát như sau:

\begin{tabular}{|c|c|c|}
\hline $\begin{array}{c}\text { Verapamil } \\
\text { hydroclorid }\end{array}$ & $:$ & Khảo sát tỉ lệ 30,40 và $50 \%$ \\
\hline Avicel $\mathrm{PH} 102$ & $:$ & $\begin{array}{c}\text { Khảo sát tỉ lệ } 35,40,45 \text { và } \\
50 \%\end{array}$ \\
\hline Lactose & $:$ & Khảo sát tỉ lệ $11 ; 12,5$ và $14 \%$ \\
\hline Talc & $:$ & Khảo sát tỉ lệ $1 ; 2,5$ và $4 \%$ \\
\hline HPMC E6 & $:$ & Khảo sát 0,$2 ; 0,4 ; 0,6$ và $0,8 \mathrm{~g}$ \\
\hline
\end{tabular}

- Tiến hành: VER.HCl, Avicel $\mathrm{PH} 102$ và lactose được nghiền thành bột mịn, rây qua rây $125 \mu \mathrm{m}$ rồi trộn đều thành hỗn hợp bột kép theo nguyên tắc đồng lượng. Tá dược trớn được nghiên mịn và phân tán vào hỗn hợp bột kép. Sau đó, cho tá dược dính lỏng từ từ vào hỗn hợp bột kép, nhào kỹ tạo khối bột có độ dẻo thích hợp. Ủ khối dẻo trong thời gian 45 phút. Sau đó, cho vào máy đùn và cắt để tạo thành các sợi ngắn. Các sợi ngắn được chuyển sang máy tạo cầu và quay máy trong thời gian thích hợp để pellet hình thành. Sây pellet ở nhiệt độ $40-50^{\circ} \mathrm{C}$ trong thời gian 4 giờ đến độ ẩm nhỏ hởn $5 \%$ rồi đem rây lấy pellet có đường kính trong khoảng 0,8 đến $1,25 \mathrm{~mm}$.

- Thông số thiết bị: với các thông số khảo sát như sau:

\begin{tabular}{|c|l|c|}
\hline Khối lượng 1 mẻ & $:$ & $100 \mathrm{~g}$ \\
\hline Thiết bị & $:$ & $\begin{array}{c}\text { máy đùn tạo câu QZT } \\
350 \text { (Trung Quốc) }\end{array}$ \\
\hline Tốc độ đùn & $:$ & 30 vòng/phút \\
\hline Đường kính mắt sàng & $:$ & $1 \mathrm{~mm}$ \\
\hline Tốc độ tạo cầu & $:$ & $\begin{array}{c}\text { Khảo sát } 300,400 \text { và } \\
500 \text { vòng/phút }\end{array}$ \\
\hline Thời gian tạo cầu & $:$ & Khảo sát 5,7 và 9 phút \\
\hline
\end{tabular}

2.3.2. Phương pháp đánh giá tiêu chuẩn chất lượng

*Hiệu suất bào chế pellet:

$\mathrm{H}=M \times 100(\%)$.

Trong đó: - m: khối lượng pellet thu được có kích thước 0,8-1,25 mm.

- M: khối lượng nguyên liệu ban đầu (trừ tá dược dính lỏng).

* Độ mài mòn: Đo bằng máy xác định độ mài mòn Pharmatest PTF 20E theo phương pháp trống quay (100 vòng trong 4 phút). Độ mài mòn được tính theo công thức:

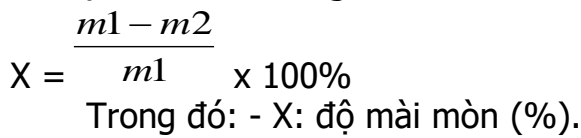

- m1: Khối lượng pellet trước khi thử (g).

- m2: Khối lượng pellet sau khi thử (g).

*Xác định độ trơn chảy: Được thực hiện trên 
máy đo tỗc độ chảy ERWEKA GWF với đường kính lỗ phễu $12 \mathrm{~mm}$. Tốc độ trơn chảy được tính theo công thức: $\mathrm{v}=\mathrm{tga}$

Trong đó: - v: tốc độ chảy (g/giây).

- a: góc giữa đường thẳng biểu diễn sự phụ thuộc của khối lượng hạt chảy theo thời gian và trục hoành (trục thời gian).

* Mất khối Iượng do làm khô: Được xác định trên cân xác định độ ẩm nhanh Sartorius MA 30. Cân khoảng $5 \mathrm{~g}$ pellet, nghiền mịn, đặt vào đĩa cân, đặt nhiệt độ $105^{\circ} \mathrm{C}$, theo dõi và đọc kêt quả.

*Khối lượng riêng biểu kiến: Xác định trên máy đo thể tích biểu kiến của hạt và bột ERWEKA SVM theo phương pháp gõ đến thể tích không đổi. Khối lượng pellet sử dụng cho mỗi lần đo là $50 \mathrm{~g}$. Công thức tính như sau:

$$
\mathrm{D}=\mathrm{m} / \mathrm{v}
$$

Trong đó: + D: Khối lượng riêng biểu kiến.

$+\mathrm{m}$ : Khối lượng pellet (gam).

+ v: Thể tích biểu kiến của pellet $(\mathrm{ml})$.

* Định lượng VER.HCl trong pellet:

- Mẫu thử: cân khoảng $2 \mathrm{~g}$ pellet, nghiền thành bột mịn. Cân chính xác lượng bột mịn tương ứng với khoảng $50 \mathrm{mg}$ VER. $\mathrm{HCl}$, cho vào cốc có mỏ $50 \mathrm{ml}$, thêm khoảng $30 \mathrm{ml}$ đệm phosphat $\mathrm{pH} 7,5$. Lắc siêu âm trong 60 phút. Chuyển vào bình định mức $50 \mathrm{ml}$, thêm đệm phosphat pH 7,5 tới vạch, lắc đều. Lọc qua giây lọc, loại bỏ khoảng $10 \mathrm{ml}$ dịch lọc đầu, được dung dịch $\mathrm{A}$. Hút chính xác $0,5 \mathrm{ml}$ dung dịch $\mathrm{A}$ cho vào bình định mức $10 \mathrm{ml}$, thêm đệm phosphat $\mathrm{pH} 7,5$ tới vạch, lắc đều, dung dịch được đem đo quang ở bước sóng $\lambda=278 \mathrm{~nm}$. Tiến hành song song với dung dịch chuẩn trong $A$ çùng điều kiện. Hàm lượng dược chất trong pellet được tính theo công thức: \% VER.HCl /pellet= Ac.mit x100 (\%)

Trong đó: - At: Mật độ quang của dung dịch thử.

- Ac: Mật độ quang của dung dịch chuẩn.

- mc: Khối lượng VER.HCl chuẩn cân để định lượng.

- mt: Khối lượng pellet cân để định lượng.

*Độ hòa tan: theo chuyên luận USP 41 với các điè̉u kiện cụ thể sau:

- Thiết bị: cánh khuây.

- Tốc độ khuấy: $50 \pm 2$ vòng/phút.

- Nhiệt độ: $37,0 \pm 0,5^{\circ} \mathrm{C}$.

- Mồi trường: $900 \mathrm{ml}$ dung dịch đệm phosphat $\mathrm{pH} 7,5$.

- Thời gian lấy mẫu: $1,2,4$ và 8 giờ.

- Mẫu thử: lượng pellet tương đương với 120 $\mathrm{mg}$ VER.HCl

- Định lượng DC giải phóng ở các thời điểm bằng phương pháp đo độ hấp thụ ở bước sóng $278 \mathrm{~nm}$. Tính lượng giải phóng $\mathrm{DC}$ căn cứ vào điểm chuẩn của VER.HCl trong môi trường đệm phosphat pH 7,5 bằng quang phổ UV-VIS [6].

III. KẾT QUẢ NGHIÊN CỨU VÀ BÀN LUẬN

3.1. Khảo sát ảnh hưởng của các tá dược trong công thức đến khả năng tạo pellet

3.1.1. Ânh hưởng của tỉ lệ dược chất đến khả năng tạo pellet

Với mục đích bào chế pellet VER.HCl GPKD đóng nang chứa $120 \mathrm{mg}$ dược chất, tiến hành khảo sát các công thức như bảng 1 .

Bảng 1. Thành phân pellet với tỉ lệ dược chất khác nhau

\begin{tabular}{|c|c|c|c|}
\hline Thành phân (\%) & $\begin{array}{l}\text { CT } \\
1.1\end{array}$ & $\begin{array}{l}\text { CT } \\
1.2\end{array}$ & $\begin{array}{l}\text { CT } \\
1.3\end{array}$ \\
\hline Verapamil $\mathrm{HCl}$ & 30 & 40 & 50 \\
\hline Avicel PH102 & 40 & 40 & 40 \\
\hline Lactose & 29 & 19 & 9 \\
\hline Talc & 1 & 1 & 1 \\
\hline $\begin{array}{l}\text { TD dính (HPMC E6 2\% } \\
\text { trong nước) }\end{array}$ & vđ & vđ & vđ \\
\hline
\end{tabular}

Thực hiện bào chế pellet với các thông số của máy đùn - tạo cầu như trong phần phương pháp bào chế pellet VER. $\mathrm{HCl}$ nhân trong mục 2.3.1 thu được kết quả như sau:

Bảng 2. Hiệu suât, cảm quan và đặc điểm pellet nhần khi khảo sát lứa chọn tỉ lệ dược chât $\left(n=5 ;{ }^{\mathrm{X}} \pm S D\right)$

\begin{tabular}{|c|c|c|c|}
\hline $\begin{array}{l}\text { Công } \\
\text { thức }\end{array}$ & $\begin{array}{l}\text { Hiệu } \\
\text { suất } \\
(\%)\end{array}$ & $\begin{array}{c}\text { Đặc điểm } \\
\text { pellet }\end{array}$ & $\begin{array}{l}\text { Đặc điểm đùn- } \\
\text { tạo câu }\end{array}$ \\
\hline CT 1.1 & $\begin{array}{l}70,96 \\
\pm 1,06\end{array}$ & $\begin{array}{l}\text { Nhiêu hât } \\
\text { câu, ít dùi } \\
\text { trống }\end{array}$ & Dễ đùn, dễ vo \\
\hline CT 1.2 & $\begin{array}{l}61,36 \\
\pm 1,05\end{array}$ & $\begin{array}{l}\text { Nhiều hat } \\
\text { câu, ít dùi } \\
\text { trống }\end{array}$ & Hơi bết dính \\
\hline CT 1.3 & $\begin{array}{l}42,91 \\
\pm 0,94\end{array}$ & $\begin{array}{l}\text { Pellet hình } \\
\text { dùi trống }\end{array}$ & $\begin{array}{c}\text { Dề dính đĩa, } \\
\text { nhiều bột mịn } \\
\text { dính thành nồi vo }\end{array}$ \\
\hline
\end{tabular}

Nhận xét: Khi tăng dần tỉ lệ DC trong thành phần bột kép thì hiệu suất tạo pellet giảm, quá trình vo tạo pellet khó khăn. Công thức CT1.1 với $30 \%$ tỉ lệ $\mathrm{DC}$ trong công thức cho hiệu suất tạo pellet cao nhất $(70,96 \%)$, quá trình đùn và vo thuận lợi, pellet tròn, đêu. Pellet tạo ra từ công thức $\mathrm{CT} 1.1$ và $\mathrm{CT} 1.2$ khá cầu, đều hơn công thức CT 1.3, có thể do khi tăng tỉ lệ dược chất trong thành phần bột kép và các thành phần còn lại giữ nguyên làm quá trình tạo pellet khó khăn, có thể giải thích do dược chất dễ tan trong nước nên khi nhào ẩm sẽ tan ra một phần và tham gia làm chất kết dính gây bết dính đĩa vo khi vo, mặt khác khi không đủ ẩm, pellet tạo thành hình dưi trống nhiều và nhiêuu bột mịn tạo 
ra gây kẹt đĩa vo. Cả hai công thức $C T 1.1$ và $C T$ 1.2 đều có khả năng tạo ra pellet cầu, tuy nhiên để thuận tiện cho việc đóng nang, nên lựa chọn công thức CT 1.2 (có hàm lượng dược chất cao hơn) để tiến hành các nghiên cứu tiếp theo.

3.1.2. Ảnh hưởng của tỉ lệ Avicel PH102 đến khả năng tạo pellet. Tá dược tạo cầu là thành phần không thể thiếu được trong công thức bào chế pellet bằng phương pháp đùn - tạo câu, trong đó Avicel PH102 là tá dược tạo cầu hay được sử dụng. Để nghiên cứu ảnh hưởng của Avicel tới khả năng tạo cầu của pellet, các công thức và kết quả được thể hiện ở bảng 3 và 4 .

Bảng 3. Thành phân pellet với tỉ lệ Avicel PH102 khác nhau

\begin{tabular}{|c|c|c|c|c|}
\hline Thành phân(\%) & CT1.2 & CT1.4 & \multicolumn{2}{|c|}{ CT1.5 CT1. } \\
\hline Vera & 40 & 40 & 40 & 10 \\
\hline Avic & 40 & 35 & 45 & \\
\hline & 19 & 24 & 14 & \\
\hline & 1 & 1 & 1 & 1 \\
\hline $\begin{array}{r}\text { ung di } \\
\text { E6 } 2\end{array}$ & 35 & 35 & 35 & \\
\hline
\end{tabular}

Bảng 4. Hiệu suât, cảm quan và đặc điểm pellet nhân khi khảo sát lựa chọn tỉ lệ phôi hợp Avicel PH102 : lactose (n=5; ${ }^{x} \pm$ SD)

\begin{tabular}{|c|c|c|c|}
\hline $\begin{array}{l}\text { Công } \\
\text { thức }\end{array}$ & $\begin{array}{c}\text { Hiệu suất } \\
(\%)\end{array}$ & $\begin{array}{c}\text { Đăcc điếm } \\
\text { pellet }\end{array}$ & $\begin{array}{c}\text { Đăc điếm } \\
\text { đùn-tạo câu }\end{array}$ \\
\hline CT 1.2 & $61,36 \pm 1,05$ & Ít cầu & $\begin{array}{c}\text { Dê đùn, ít dính } \\
\text { nồi vo }\end{array}$ \\
\hline CT 1.4 & $43,68 \pm 1,20$ & $\begin{array}{l}\text { Không cầu, } \\
\text { thô ráp }\end{array}$ & $\begin{array}{l}\text { Đùn dính sợi, } \\
\text { vo dính đĩa vo }\end{array}$ \\
\hline CT 1.5 & $64,83 \pm 0,93$ & $\begin{array}{c}\text { Pellet cầu, } \\
\text { nhẵn }\end{array}$ & $\begin{array}{c}\text { Dê đùn, ít dính } \\
\text { nồi vo }\end{array}$ \\
\hline CT 1.6 & $54,72 \pm 0,94$ & $\begin{array}{c}\text { Ít cầu, } \\
\text { nhiều bột } \\
\text { mịn }\end{array}$ & $\begin{array}{c}\text { Sợi đùn khô, } \\
\text { sinh nhiều bột } \\
\text { mịn khi vo, vo } \\
\text { dính đĩa }\end{array}$ \\
\hline
\end{tabular}

Nhận xét: Trong công thức, Avicel PH 102 là tá dược tạo cầu, với cùng một lượng thể tích dung dịch tá dược dính, khi dùng ở tỉ lệ thấp sẽ không đủ để tạo độ cầu cho pellet, tăng dân tỉ lệ Avicel PH102 thì pellet cũng tăng độ cầu, tuy nhiên khi dùng ở tỉ lệ cao khiến khối bột khô, có thể do thiếu ẩm để Avicel PH102 trương nở tạo độ cầu làm sợi đùn khô sinh nhiều bột mịn, đồng thời pellet chứa Avicel ở tî lệ cao có thể ảnh hưởng đến sự giải phóng dược chất từ pellet. Theo bảng trển, công thức CT 1.5 là công thức có tỉ lệ Avicel PH102 thích hợp nhất cho pellet cầu và bề mặt khá nhẵn, vì vậy, công thức pellet với tî lệ Avicel PH102 45\% sẽ được sử dụng trong những khảo sát tiếp theo.

\subsection{3. Ânh hưởng của tỉ lệ tá dược dược}

trơn đến khả năng tạo pellet. Để khảo sát ảnh hưởng của tỉ lệ tá dược trơn dùng trong công thức tạo pellet, các công thức giữ nguyên tỉ lệ dược chất, Avicel $\mathrm{PH} 102$, lactose và tá dược dính, thay đổi tỉ lệ tá dược trơn. Các công thức và kết quả được thể hiện ở bảng 5 và 6 .

Bảng 5. Thành phần pellet với tỉ lệ tá dược trơn khác nhau

\begin{tabular}{|c|c|c|c|}
\hline $\begin{array}{c}\text { Thành phân } \\
\text { (\%) }\end{array}$ & CT1.5 & CT1.7 & CT1.8 \\
\hline Verapamil HCl & 40 & 40 & 40 \\
\hline Avicel PH102 & 45 & 45 & 45 \\
\hline Lactose & 14 & 12,5 & 11 \\
\hline Talc & 1 & 2,5 & 4 \\
\hline $\begin{array}{c}\text { Dung dịch HPMC } \\
\text { E6 2\% (ml) }\end{array}$ & vđ & vđ & vđ \\
\hline
\end{tabular}

Bảng 6. Hiệu suât, cảm quan và đặc điểm pellet nhân khi khảo sát lựa chọn tỉ lệ tá dước trơn khác nhau $\left(n=5 ;{ }^{2} \pm S D\right)$

\begin{tabular}{|c|c|c|c|}
\hline $\begin{array}{l}\text { Công } \\
\text { thức }\end{array}$ & $\begin{array}{l}\text { Hiệu } \\
\text { suất } \\
(\%)\end{array}$ & $\begin{array}{l}\text { Đặc điểm } \\
\text { pellet }\end{array}$ & $\begin{array}{c}\text { Đăcc điếm } \\
\text { đùn-tạo } \\
\text { câu }\end{array}$ \\
\hline $\begin{array}{l}\mathrm{CT} \\
1.5\end{array}$ & $\begin{array}{l}64,83 \\
\pm 0,93 \\
\end{array}$ & $\begin{array}{c}\text { Pellet cầu, } \\
\text { nhẵn }\end{array}$ & $\begin{array}{l}\text { Dê đùn, ít } \\
\text { dính nồi vo }\end{array}$ \\
\hline CT1.7 & $\begin{array}{l}70,81 \\
\pm 0,90\end{array}$ & $\begin{array}{l}\text { Pellet cầu, } \\
\text { nhẵn, đồng } \\
\text { đều, }\end{array}$ & $\begin{array}{l}\text { Không dính } \\
\text { máy }\end{array}$ \\
\hline CT1.8 & $\begin{array}{l}68,47 \\
\pm 0,82\end{array}$ & $\begin{array}{l}\text { Pellet ít câu, } \\
\text { nhiều hạt to, }\end{array}$ & $\begin{array}{l}\text { Không dính } \\
\text { máy }\end{array}$ \\
\hline
\end{tabular}

Nhận xét: Tá dược trớn (talc) có vai trò quan trọng trong bào chế pellet theo phương pháp đùn tạo - cầu, tá dược trơn làm giảm ma sát giữa bề mặt của khối bột ẩm bị ép sợi với bề mặt sàng, giúp cho khối bột ẩm đi qua trục ép đùn và lố mắt sàng dễ dàng hơn để tạo ra các sợi ép hình trụ không dính lại với nhau và không dính sàng, đồng thời làm giảm sự sinh nhiệt do ma sát trong quá trính ép đùn. Trong quá trình tạo cầu, tá dược trơn giúp cho các đoạn sợi hình trụ không dính vào nhau và tạo được độ cầu. Từ các kết quả bảng trên cho thấy, khi dùng talc ở tî lệ $2,5 \%$ cho pellet cầu đều và hiệu suất cao nhất, dùng ở tỉ lệ $1 \%$ pellet bị dính nhau và dính máy làm kích thước không đồng đều và hiệu suất thấp, mặt khác khi dùng talc ở tỉ lệ cao hớn là 4,5\%, pellet không dính máy nhưng ít cầu và nhiều hạt to, có thể giải thích hiện tượng này do thừa tá dược trơn, đĩa ma sát quay tròn trong khi các pellet chuyển động chậm lại hoặc đông tụ với nhau thành khối, làm giảm độ cầu của sản phẩm, hoặc kết tụ lại với nhau thành hạt to.

3.1.4. Ảnh hưởng của lượng tá dược dính đến khả năng tạo pellet

Tiến hành khảo sát ảnh hưởng của lượng tá 
dược dính đến khả năng tạo câu, các thành phân VER.HCl, Avicel PH 102, lactose và talc giứ nguyên, lượng HPMC E6 được thay đổi ở các lượng khác nhau với cùng một thể tích nước. Các công thức và kết quả được thể hiện ở bảng 7 và 8 .

Bảng 7. Thành phân pellet với tỉ lệ HPMC E6 khác nhau

\begin{tabular}{|c|c|c|c|c|}
\hline $\begin{array}{c}\text { Thành phân } \\
(\%)\end{array}$ & $\begin{array}{c}\text { CT } \\
\mathbf{1 . 9}\end{array}$ & $\begin{array}{c}\mathbf{C T} \\
\mathbf{1 . 1 0}\end{array}$ & $\begin{array}{c}\mathbf{C T} \\
\mathbf{1 . 1 1}\end{array}$ & $\begin{array}{c}\mathbf{C T} \\
\mathbf{1 . 1 2}\end{array}$ \\
\hline Verapamil HCl & 40 & 40 & 40 & 40 \\
\hline Avicel PH102 & 45 & 45 & 45 & 45 \\
\hline Lactose & 12,5 & 12,5 & 12,5 & 12,5 \\
\hline Talc & 2,5 & 2,5 & 2,5 & 2,5 \\
\hline HPMC E6 (g) & 0,8 & 0,6 & 0,4 & 0,2 \\
\hline $\begin{array}{c}\text { Nước tinh } \\
\text { khiết (ml) }\end{array}$ & 50 & 50 & 50 & 50 \\
\hline
\end{tabular}

Bảng 8. Hiệu suât, cảm quan và đặc điểm pellet nhân khi khảo sát lưa chọn tỉ lệ HPMC E6 khác nhau $(n=5 ; \quad \pm S D)$

\begin{tabular}{|c|c|c|c|}
\hline $\begin{array}{l}\text { Công } \\
\text { thức }\end{array}$ & $\begin{array}{c}\text { Hiệu suất } \\
(\%)\end{array}$ & $\begin{array}{c}\text { Đăcc điếm } \\
\text { pellet }\end{array}$ & $\begin{array}{c}\text { Đắc điểm } \\
\text { đùn-tạo câu }\end{array}$ \\
\hline CT1.9 & $42,30 \pm 1,41$ & $\begin{array}{l}\text { Pellet không } \\
\text { đồng đều }\end{array}$ & $\begin{array}{c}\text { Sợi đùn dính, } \\
\text { vo bết, dính } \\
\text { thành máy } \\
\text { nhiều. }\end{array}$ \\
\hline CT1.10 & $47,21 \pm 1,10$ & $\begin{array}{c}\text { Pellet không } \\
\text { đồng đều }\end{array}$ & $\begin{array}{c}\text { Vo bết dính } \\
\text { thành máy và } \\
\text { đĩa vo. }\end{array}$ \\
\hline СТ1.11 & $61,15 \pm 1,56$ & Pellet to & $\begin{array}{l}\text { Vo dính các } \\
\text { hạt, ít dính } \\
\text { thành máy. }\end{array}$ \\
\hline СТ1.12 & $81,30 \pm 1,30$ & $\begin{array}{l}\text { Pellet câu } \\
\text { đều, đẹp , bề } \\
\text { mặt nhắn. }\end{array}$ & $\begin{array}{l}\text { Đùn và } \\
\text { vo dê̂. }\end{array}$ \\
\hline
\end{tabular}

Nhân xét: Lượng tá dược dính sư dưng cân vừa đủ để đảm bảo vừa giúp các tiểu phân dược chất và tá dược liên kết với nhau, vừa đảm bảo đủ để Avicel PH102 trương nở hoàn toàn tạo độ câu cho pellet. Kết quả cho thấy CT1.12 cho hiệu suất pellet cao nhất và cảm quan đẹp nhất, quá trình đùn-vo dễ dàng, pellet hình thành cầu đẹp, bề mặt nhẵn mịn. Các công thức còn lại đùn-vo khó khăn, pellet bết dính, hiệu suất thấp do thừa lượng tá dính làm pellet dính nhau và dính máy. Như vậy, công thức CT1.12 là công thức có tỉ lệ phù hợp nhất, cho pellet cảm quan tốt nhất, được chọn để đánh giá các tiêu chuẩn tiếp theo.

3.2. Khảo sát ảnh hưởng của thông số thiết bị đến khả năng tạo pellet

3.2.1. Ânh hưởng của thời gian tạo câu đến khả năng tạo pellet

Sử dụng công thức CT 1.12, tiến hành bào chế pellet VER.HCl. Sau đó khảo sát thời gian tạo câu lân lượt là 5 phút, 7 phút và 9 phút. Kết quả được thể hiện ở bảng 9.

Bảng 9. Kêt quả ảnh hưởng của thời xian tạo câuu đến khả năng tạo pellet (n=5; \pm SD)

\begin{tabular}{|c|c|c|}
\hline $\begin{array}{c}\text { Thời gian tạo } \\
\text { câu (phút) }\end{array}$ & $\begin{array}{c}\text { Hiệu suất } \\
\mathbf{( \% )}\end{array}$ & Đặc điểm pellet \\
\hline 5 & $\begin{array}{c}84,94 \\
\pm 1,09\end{array}$ & $\begin{array}{c}\text { Nhiều pellet kích } \\
\text { thước nhỏ }\end{array}$ \\
\hline 7 & $\begin{array}{c}93,77 \\
\pm 1,19\end{array}$ & $\begin{array}{c}\text { Pellet tròn, chắc, bề } \\
\text { mặt bóng mịn }\end{array}$ \\
\hline 9 & $\begin{array}{c}82,01 \\
\pm 0,87\end{array}$ & $\begin{array}{c}\text { Tạo bóng cầu lớn, } \\
\text { dễ dính }\end{array}$ \\
\hline
\end{tabular}

Kết quả bảng 3.15 cho thấy: Khi thời gian tạo câu ngắn (5 phút), hiệu suất tạo pellet là $84,94 \%$, pellet sinh ra có nhiêu hạt nhỏ kích thước dưới 0,8 mm. Còn khi thời gian tạo câu dài (9 phút) hiệu suất tạo pellet là $82,01 \%$ pellet sinh ra nhiếu bóng cầu lớn do các hạt dính vào nhau, kết tụ và dính vào thành máy làm cho khối pellet chuyển động không tròn đều. Thời gian tạo câu 7 phút cho hiệu suất tạo pellet là cao nhất (93,77\%), chất lượng pellet tốt hơn. Vì vậy, thời gian tạo câu là 7 phút được lựa chọn cho các nghiên cứu tiếp theo.

3.2.2. Ảnh hưởng của tốc độ tạo câu đến khả năng tạo pellet. Vẫn sử dụng công thức CT 1.12, cố định thời gian tạo câu là 7 phút, tiến hành bào chế pellet VER. $\mathrm{HCl}$. Sau đó khảo sát tốc độ tạo câu lân lượt là 300 vòng/phút, 400 vòng/phút và 500 vòng/phút. Kết quả được thể hiện ở bảng 10.

Bảng 10. Kêt quả ảnh hưởng củątốc độ tạo câuu đến khả năng tạo pellet $\left(n=5 ;^{\times} \pm S D\right)$

\begin{tabular}{|c|c|c|}
\hline $\begin{array}{c}\text { Tốc độ tạo câu } \\
\text { (vòng/ phút) }\end{array}$ & $\begin{array}{c}\text { Hiệu suất } \\
\text { (\%) }\end{array}$ & $\begin{array}{c}\text { Đắc điếm } \\
\text { pellet }\end{array}$ \\
\hline 300 & $89,30 \pm 0,78$ & $\begin{array}{c}\text { Nhiêu hạt hình } \\
\text { gậy }\end{array}$ \\
\hline 400 & $93,77 \pm 1,19$ & $\begin{array}{c}\text { Pellet tròn, } \\
\text { chắc, bề mặt } \\
\text { bóng mịn }\end{array}$ \\
\hline 500 & $86,62 \pm 0,67$ & \begin{tabular}{c} 
bòn \\
\cline { 1 - 2 }
\end{tabular}
\end{tabular}

Kết quả bảng 3.16 cho thây: Tốc độ tạo câu chậm 300 vòng/phút hiệu suất tạo pellet là 89,30\% pellet thu được ít có dạng hình câu, nhiều pellet hình gậy. Khi tốc độ tạo câu là 500 vòng/phút hiệu suất tạo pellet là $86,62 \%$, pellet thu đước có kích thước > 1,25 mm nhiều do khi tốc độ tạo câuu lớn làm các hạt pellet kết tụ lại với nhau, làm tăng lượng pellet có kích thước lớn. Tốc độ tạo câu 400 vòng/phút là phù hợp, chất lượng pellet thu được tốt, hiệu suất tạo pellet cao (93,77\%). Vì vậy, tốc độ tạo câu là 400 vòng/phút được lựa chọn cho các nghiên cứu tiếp theo.

3.3. Đánh giá tiêu chuẩn của pellet 
VER.HCl nhân. Pellet VER.HCl bào chế theo công thức CT $1.12(300 \mathrm{~g} / \mathrm{mẻ})$ được sấy ở 50$55^{\circ} \mathrm{C} / 8$ giờ, rây chọn và đánh giá giá một số chỉ tiêu khác thu được các kết quả như bảng 11.

\begin{tabular}{|c|c|}
\hline Đăc tính & Kết quả \\
\hline Hình thức & $\begin{array}{l}\text { Pellet tròn đều, bề } \\
\text { mặt nhẵn, mịn, kích } \\
\text { thước } 0,8-1,2 \text { mm }\end{array}$ \\
\hline $\begin{array}{l}\text { Khối lượng riêng biếu } \\
\text { kiến }(\mathrm{g} / \mathrm{ml})\end{array}$ & $0,72 \pm 0,06$ \\
\hline Tốc độ chảy $(\mathrm{g} / \mathrm{s})$ & $0,74 \pm 0,09$ \\
\hline Độ mài mòn (\%) & $0,22 \pm 0,08$ \\
\hline Hàm ẩm (\%) & $2,86 \pm 0,11$ \\
\hline $\begin{array}{l}\text { Hàm lượng VER.HCl } \\
\text { trong pellet (\%) }\end{array}$ & $38,45 \pm 0,57$ \\
\hline $\begin{array}{c}\text { Tỷ lê pellet có kích } \\
\text { thước } 0,8-1,2 \mathrm{~mm}(\%)\end{array}$ & $77,22 \pm 1,10$ \\
\hline \multicolumn{2}{|l|}{ Độ hòa tan (\%): } \\
\hline 10 phút & $80,76 \pm 1,51$ \\
\hline 20 phút & $93,38 \pm 1,57$ \\
\hline 30 phút & $97,33 \pm 0,90$ \\
\hline & $99,91 \pm 1,56$ \\
\hline
\end{tabular}

Nhận xét: Pellet thu được đem lấy phân đoạn có kích thước trong khoảng $0,8-1,2 \mathrm{~mm}$ và đem đánh giá thử độ hòa tan các thời điểm lây mẫu là: $10,20,30$ và 60 phút. Pellet VER. $\mathrm{HCl}$ nhân bào chế theo phương pháp đùn tạo câu (CT1.12) thì sau 30 phút VER.HCl nhân gẩn như đã được giải phóng hoàn toàn, pellet VER.HCl nhân chưa có khả năng kéo dài giải phóng dược chất. Các pellet đạt các chỉ tiêu trên sẽ được sử dụng để bao kiểm soát giải phóng.

\section{KẾT LUÂN}

- Đã khảo sát và đánh giá được ảnh hưởng của thành phần công thức đến tính chất của pellet VER. $\mathrm{HCl}$ nhân gồm có: Verapamil $\mathrm{HCl}$, Avicel PH102, Lactose, Talc, HPMC E6 và nước tinh khiết. Ảnh hưởng thông số qui trình thiết bị gồm có: Tốc độ tạo câu và thời gian tạo cầu

- Trên cơ sở các kết quả khảo sát ảnh hưởng của các yếu tố đến tính chất của pellet VER.HCl nhân, đã xây dựng được tính chất cho pellet nhân như bảng 11 .

\section{TÀI LIẸU THAM KHẢO}

1. Bộ Y tế (2009), Dược lý học, NXB Giáo dục Việt Näm, Hà Nội, 72-74.

2. Martindale The Complete Drug Reference (2014) Thirty-eighth Edition 1522-1526.

3. BNF 73 (2017) Monograph: Verapamil hydrochloride, Pharmaceutical Press, London, 155-156.

4. Bhalekar M. R., Avari J., Umalkar R. A. (2007), Preparation and in vitro Evaluation of Sustained Release Drug Delivery System for Verapamil HCl, Indian J. Pharm. Sci., 69 (3): 418-422.

5. Nitin D. J., Dipak D. G., Ashish A. H. et al. (2010), Formulation development and evaluation of sustained release pellets of verapamil hcl, International Journal of Pharma Research and Development, 1(11): 1-7.

6. USP 41-NF 36 (2018), Monographs:Verapami hydrochlorid extended release tablets, 4307-4311.

\section{NGHIÊN CỨU IN VITRO KHẢO SÁT TÌNH TRANG GÃY DỤNG CỤ TRONG SỬA SOẠN ỐNG TỦY Ở HỆ THỐNG TRÂM PROTAPER QUAY TAY}

\section{TÓM TẮT}

Mục tiêu: Nghiên cứu nhằm khảo sát tình trạng gãy dụng cụ trong sửa soạn ống tủy ở hệ thống trâm Protaper quay tay. Đối tượng và phương pháp: Nghiên cứu in vitro được thực hiện trên 50 ống tủy gần (bao gồm cả ngoài gần và trong gần) của chân gân răng cối lớn hàm dưới ở người trưởng thành, chân răng nguyên ven, đã đóng chóp, có ống tuý cong trong khoảng $10^{\circ}-40^{\circ}$ theo phương pháp Schneider 1971. Các ống tủy gân được sửa soạn tới dụng cụ F3.

* Đai hoc Y Dược TP Hồ Chí Minh

Chịu trách nhiệm chính: Nguyễn Thu Thủy

Email: ntthuy@ump.edu.vn

Ngày nhậ bài: 5/3/2021

Ngày phản biên khoa hoc: 1/4/2021

Ngày duyệt bài: 3/5/2021

\section{Nguyễn Thu Thủy*}

Mỗi bộ protaper sẽ được thao tác cho đến khi có dụng cụ trong bộ đang thực hiện bị gãy. Số lượng ống tủy đã̃ được thao tác ở mối bộ sẽ được ghi nhận. Răng có chứa mảnh gãy sẽ được phân tích qua phim Cone Beam Computed Tomography Scan (CBCT) để xác định độ dài mảnh gãy, đồng thời xác định tương quan của mảnh gãy với chóp răng và miệng lố tủy. Kết quả: Số lượng ống tủy được sửa soạn tối đa là $10 \pm 2.7$ ống tủy. Chiêu dài mảnh gãy trung bình là $2.13 \pm 1.26 \mathrm{~mm}$. Khoảng cách trung bình từ đỉnh mảnh gãy tới chóp răng là $3.09 \pm 1.60 \mathrm{~mm}$. Khoảng cách trung bình từ đâu mảnh gãy tới miệng ống tủy là $5.97 \pm 1.84 \mathrm{~mm}$. Dụng cụ có suất độ gãy nhiều nhất là trâm S1. Kết luân: Khả năng gãy ở hệ thống trâm Protaper quay tay xảy ra khi dụng cụ đã sứa soạn $10 \pm 2.7$ ống tủy. Không có dụng cụ nào bị gãy trong lần sửa soạn đâu tiên. Dụng cụ có suất độ gãy nhiều nhất là trâm S1. Khi sự cố gãy dung $\mathrm{cụ} \mathrm{xảy} \mathrm{ra,} \mathrm{chiều}$ 